\title{
AS RELAÇÕES ENTRE ARTE E TECNOLOGIA: A DANÇA HÍBRIDA DO CENA 11
}

\author{
Elisa ABRÃo*
}

RESUMO

\begin{abstract}
O presente trabalho busca compreender as relações estabelecidas entre tecnologia e arte a partir da proposta de dança híbrida da Companhia de Dança Cena 11, de Florianópolis. Para tanto, analisamos espetáculos e a preparação física dos dançarinos a partir da observação de um conjunto de treinos e entrevistas realizadas com os integrantes do grupo, aproveitando parte de uma pesquisa de dissertação de Mestrado em Educação Física pela Universidade Federal de Santa Catarina. Neste artigo, destacamos dois eixos para a análise desta relação. O primeiro aborda a compreensão do grupo sobre as tecnologias como extensão do corpo; o segundo versa sobre as funções assumidas pelas tecnologias na arte do grupo e as implicações para aqueles sujeitos envolvidos, mediante a concepção de arte presente no grupo.
\end{abstract}

PALAVRAS-CHAVES: arte - dança híbrida - tecnologia.

\section{INTRODUÇÃO}

$\mathrm{O}$ diálogo da dança com a tecnologia é significativo e constitui-se, na dança contemporânea, como tendência identificada por dança híbrida ou tecnológica. Nessa tendência, o corpo que dança estabelece relações com a tecnologia, e pode tanto limitar quanto possibilitar múltiplas relações. Esse tema mostra-se atual e questionador, no universo das práticas artísticas e corporais. Perceber como a dança, assim como outros inúmeros fenômenos artísticos, dialoga com as novas tecnologias

\footnotetext{
Mestre em Educação Física pela Universidade Federal de Santa Catarina na linha de Teoria e Prática Pedagógica.
} 
possibilita observar modificações não só na própria arte, como também nas fronteiras que se estabelecem entre ser humano e máquina.

As modificações nessas fronteiras fizeram-nos procurar grupos que utilizavam a tecnologia como possibilidade para a linguagem artística. Assim, partimos da proposta do Cena 11 Cia. de Dança de Florianópolis, como um campo exemplar para essa análise. O objetivo central deste trabalho é analisar as relações entre arte e tecnologia, com base na dança híbrida, da qual o Grupo Cena 11 é exemplar.

A pesquisa caracteriza-se, assim, como descritivo-exploratória, conta com um estudo de caso desenvolvido a partir da proposta do Grupo Cena 11. Para isso, observamos um conjunto de treinos, ensaios, espetáculos ao vivo, vídeos do grupo e entrevistas semi-estruturadas com coreógrafo e dançarinos, de modo a estruturar alguns eixos para a análise desse conteúdo.

É importante ressaltar que, mais do que pesquisar o Grupo Cena 11, pretendemos analisar a tendência de relacionar dança e tecnologia, que emana atualmente, em certa medida, como tendência crescente e merecedora de análise, porém, não iniciada atualmente, mas que se desenha de forma particular pelas expectativas concretas de nosso tempo, pelas possibilidades tecnológicas existentes e pelo valor positivo assumido por ela hoje.

\section{A TECNOLOGIA NA ARTE DO CENA 11: UMA EXTENSÃO DO CORPO}

Essa companhia assume publicamente ser parte de uma esfera específica da dança, na qual a tecnologia já está incorporada e é entendida como possibilidade para o universo artístico. Assume, portanto, a tecnologia como "marca registrada" de sua arte como também acompanha a própria idéia de arte para o grupo.

Em uma de suas entrevistas o coreógrafo do grupo, foi questionado sobre a função de recursos como patins, câmeras, projeções de slides e a importância dessas mesclas, ao que ele respondeu:

são extensões do corpo. Eles surgem de uma maneira circunstancial, mas também estimulados pelo pensamento que a gente está tendo. 
Como nossa dança é em função do corpo, tudo aquilo que seja necessário dar a ele para que consiga manifestar a idéia com mais propriedade, não temos pudor de usar. E claro que isso tem um tratamento estético vinculado aos créditos que damos para a coisa (AHMED, 2003, p. 43).

As tecnologias compreendidas como extensões do corpo permeiam a construção artística do grupo. As tecnologias que são extensões do ser humano engendram modificações nas relações estabelecidas na organização social. Pense-se em uma extensão pontual, o vestuário. Certamente, o vestuário exerce a função de agasalhar, ou seja, "o vestuário, como extensão da pele, pode ser visto como um mecanismo de controle térmico e como meio de definição do ser social" (MCLUHAN, 2005, p. 140). Essas são idéias que parecem compreendidas pelo grupo, mas o vestuário também interfere em outros meios e extensões do ser humano na sociedade, pois as extensões do ser humano são produtores de acontecimentos que modificam as relações estabelecidas socialmente.

A roupa é uma forma de manifesto não verbal, que pode engendrar relações diante de sua utilização. A não-utilização da roupa diante de toda a carga de sensibilidade altamente visual e retorcida das sociedades industriais faz com que o contato visual com a pele possa ser algo chocante. Nos espetáculos do grupo, a nudez participa da composição cênica. Em uma das cenas de Skinnerbox ${ }^{1}$, um dos dançarinos da companhia entra nu, e acoplado a seu corpo somente há um par de sapatos de palhaço vermelhos. Apesar de serem sapatos extremamente chamativos e provocantes, a atenção de alguns espectadores ${ }^{2}$ voltou-se para o fato de o corpo do dançarino estar nu, por isso causar certo incômodo. Sobre isso, o dançarino comenta:

Aquela cena do nu sozinho ali numa luz branca, o que tem ali de mais que chama a atenção deveria ser o sapato, que é vermelho, que é também um sapatão bem grandão. E às vezes, a pessoa está tão interessada, tão incomodada com a situação que ela de repente... ninguém falou do meu sapato vermelho.

Assim, as utilizações de roupas que são extensões do corpo e que produzem acontecimentos engendram relações e sentidos ao corpo em 
si. O corpo que dança no Grupo Cena 11 vem dialogando com muitas das possibilidades de extensões criadas socialmente. Para muito além das roupas, equipamentos de tecnologia mais elaborados, como robôs, vêm compondo a organização cênica do grupo. As tecnologias são consideradas pelo grupo como forma de ampliar a maneira de comunicar.

A perspectiva imediata para o homem ocidental, letrado e fragmentado, ao defrontar-se com a implosão elétrica dentro de sua própria cultura, é a de transformar-se rápido e seguramente numa criatura profundamente estruturada e complexa, emocionalmente consciente de sua total interdependência em relação ao resto da sociedade (MCLUHAN, 2005, p. 69).

Sabe-se que muitas das extensões possíveis são consideradas possibilidade para a autonomia do ser humano diante da organização social. Assim, muitas das extensões produzidas socialmente adentram a produção artística do Grupo Cena 11. O diálogo com essas extensões vem carregado de múltiplas possibilidades e, no particular da arte do Cena 11, em muitos momentos, as extensões recebem destaque frente à organização da arte do grupo.

Como ilustra a análise do Espetáculo SKR - Procedimento $01,{ }^{3}$ o tratamento estético dado à tecnologia pelo grupo, em alguns momentos, parece ressaltar as tecnologias em si. No espetáculo em questão, do total de 25 cenas, ${ }^{4}$ apenas 12 não apresentam o uso de equipamentos tecnológicos, ${ }^{5}$ quatro são somente constituídas por equipamentos tecnológicos e nove consideram-se mistas, as quais compõem-se por dançarinos e equipamentos tecnológicos. Os indicadores mostram o número de 13 cenas, nas quais estão presentes equipamentos tecnológicos e um número menor, 12, sem a presença deles. Esses dados indicam uma possível analogia entre o universo tecnológico e o artístico, na arte do Cena 11.

Além da presença marcante das tecnologias na arte da companhia, a busca por um corpo eficiente para realizar a técnica corporal desenvolvida pelo grupo parece fortalecida pela utilização das tecnologias. O entusiasmo diante das tecnologias, na crença da superação dos limites físicos, principalmente diante das possibilidades das tecnologias digitais, parece florescer na arte do Cena 11. Esse entusiasmo é observado em muitas das relações humanas atuais. A eficiência das tecnolo- 
gias digitais parece ter fortalecido sua utilização ou ser a argumentação para fundar seu predomínio em nossa sociedade.

De uma tecnologia de base física, como a analógica, que na execução de trabalhos ou no gozo do lazer demandava de homens e mulheres habilidades, destrezas físicas, treináveis ao longo da vida, passa-se para uma nova e desafiadora situação em que a demanda se volta a qualificações mentais, à capacidade de abstração (BIANCHETTI, 2001, p. 13).

Assim, as relações do seres humanos com as tecnologias modificaram as exigências de qualidades humanas para tal relação ocorrer. Parece que a pretensão do grupo é a utilização da tecnologia cada vez mais automatizada. Como comenta uma das integrantes do grupo: "A gente trabalha meio no que o Álvaro ${ }^{6}$ chama de tecnologia do artesanato. A gente gostaria muito que as estruturas se movimentassem em cima das pessoas (risos), mas não é uma realidade tão próxima”. O grupo parece entusiasmado diante das possibilidades tecnológicas e de toda a eficiência existente em tal universo. Uma grande questão para o grupo é o acesso ainda ser restrito às tecnologias, situação também enfrentada por relevante parte da sociedade, que busca interminavelmente mais qualidade tecnológica.

Neste novo contexto pessoas e instituições [...] são levadas, por opção ou pela compulsoriedade a que são submetidos todos aqueles que pretendem manter-se coetâneos (as) ao seu tempo, a rever formas, métodos de ensinar e aprender - na escola e no trabalho -, uma vez que a tradição, a experiência e a formação/treinamento pontual deixaram de ser critério de qualificação para a vida/trabalho (BIANCHETTI, 2001, p. 13).

Isso, em certa medida, pode ser observado na arte do Grupo Cena 11. Apesar de o grupo em questão ter um treinamento físico específico, até mesmo por se tratar de dança na qual o corpo, até o momento, fazse necessário para ela ser realizada, parece que também as tecnologias vêm adentrando suas produções e criando novas relações e métodos para o universo da dança. Assim, os saberes desenvolvidos nas áreas tecnológicas tornam-se tão necessários quanto os artísticos, apesar dos limitantes financeiros. Ilustra essas relações entre o universo artístico e tecnológico na arte do grupo a fala de uma de suas dançarinas: 
Eu sei que dentro do que a gente pode estar fazendo estamos fazendo o melhor que a gente consegue. Mas eu gostaria que fosse melhor, pois acho a coisa ainda muito devagar. O robô podia ser... se tivesse alguém dessa área trabalhando junto, desenvolvendo, seria melhor. Não que ele esteja ruim, mas eu tinha na minha cabeça [que], se a gente tivesse mais dinheiro pra comprar o nosso projetor, a nossa luz, essa coisa tecnológica seria sempre a mesma, sempre seria a mesma qualidade de imagem, mas como a gente tem que locar o projetor em cada espetáculo, então, tem cidade a que tu chegas, olhas daquele jeito a definição. Então, eu acho que a gente podia construir mais, se tivesse uma sede, um lugar pra deixar tudo montado. Ia partir pra um outro lugar.

Demonstra-se a vontade do grupo de desenvolver e ampliar essa relação com as possibilidades tecnológicas, tanto pelo desejo de adquirir os aparatos tecnológicos quanto de contratar um especialista na área. Assim, compreendemos que a Companhia Cena 11 almeja o que, de certa forma, é pretensão vigente em nossa sociedade: que as tecnologias digitais predominem sobre as analógicas. A grande vantagem da linguagem binária está no maior diálogo entre os aparatos tecnológicos, que possibilita encurtar espaço e tempo, além de oferecer uma automatização tão desejada.

As tecnologias fazem parte da história da humanidade, e não se quer negá-las, mas se acha necessário que o entusiasmo diante de todos esses avanços seja crítico, capaz de compreender as contradições presentes no desenvolvimento das tecnologias. Deve-se não tê-las como imprescindíveis para o ato de dançar, e sim como possibilidade de ampliar algumas relações que estabelecemos com o mundo enquanto dançamos. Entretanto, elas podem, em alguns momentos, limitar o fazer artístico.

A utilização da tecnologia na dança soa como algo natural, nas palavras de um dos integrantes da Companhia:

Eu acho que, desde que surgiu essa tecnologia, ela já começou ser usada pela arte. Isso tem a ver com o trânsito entre ciência e arte. Então, esse trânsito sempre ocorreu de uma forma ou outra. Sempre houve cientistas interessados em arte e artistas interessados em ciência, e esse trânsito, de alguma forma, sempre em algum ponto, convergiu para que 
se produzisse algo. Então, tem uma tendência pra o quanto a tecnologia evolui, e os modos de produzir arte também se diferenciam.

Assim, a ciência parece validar a arte por meio da tecnologia, legitimação em certa medida necessária, em um mundo cada vez mais tecnocrata, onde a ciência valida verdades e determina comportamentos. A presença das tecnologias na vida das pessoas e no universo da dança passa despercebida com o decorrer do tempo, pois o maior uso e a maior quantidade de aparatos levam à naturalização dela.

Uma das dançarinas mais antigas do grupo comenta que:

Desde o primeiro espetáculo que a gente fez, já tinha microfone, música ao vivo. O Álvaro sempre pensou desse jeito, então, é uma coisa que não surpreende mais. Dizer tem vídeo é igual a dizer tem uma roupa, está normal [...] tá bem incorporado assim.

Assim, as tecnologias, como vídeo, são compreendidas pelo grupo como tão construtoras da arte quanto o ato de dançar, semelhantes às tecnologias que já passam despercebidas, como roupas, iluminação. Tal compreensão parece afirmar a hipótese de compreensão da relação de diálogo entre o universo tecnológico e artístico pelo grupo.

\section{AS FUNÇÕES DAS TECNOLOGIAS NA ARTE DO CENA 11}

A tecnologia, de forma geral, permeia a vida das pessoas, como também as relações interpessoais, não estando ausente nas artes. A presença das tecnologias na vida das pessoas e no universo da dança aparece de forma concreta na arte do grupo, e muitos recursos tecnológicos dele já se dissolveram e passam despercebidos. Para questionar as diversas funções assumidas na utilização das tecnologias acopladas ao corpo na arte do Cena 11, parte-se de uma reflexão de Tomaz Tadeu da Silva (2000, p.14):

As tecnologias ciborguianas podem ser: 1. restauradoras: permitem restaurar funções e substituir órgãos e membros perdidos; 2. normalizadoras: retornam as criaturas a uma indiferente normalidade; 3 . reconfiguradoras: criam criaturas pós-humanas, que são iguais aos seres humanos e, ao mesmo tempo, diferentes deles; 4. melhoradoras: criam criaturas melhoradas, relativamente ao ser humano. 
A arte do Grupo Cena 11 é permeada por muitas dessas possibilidades citadas por Silva (2000) no uso das tecnologias. Percebemos que muitas das intervenções, modificações sobre o corpo, que vêm ocorrendo, sobretudo na modernidade, justificam a denominação pós-humano, mas se questiona se, ao fazer isso, não se estaria negando o próprio caráter histórico do humano.

Spanghero utiliza o termo "pós-humano" para referir-se aos dançarinos do Cena 11, aproximando-os da idéia de hologramas, na descrição da coreografia Violência. ${ }^{7}$ A autora corrobora a idéia proposta por Tomaz Tadeu da Silva, ao usar esse termo, pois acoplados aos corpos dos dançarinos da companhia estão: pernas e braços metálicos, bogobol, patins, separador bucal, botas, joelheiras, dentre outros recursos. "Essas peças artificiais tornam seus corpos mais altos, mais fortes, amplificados, assimétricos, capazes de pular, virar míssil e se arremessar. As próteses thes garantem superpoderes e com elas sua dança é feita" (SPANGHERO, 2003, p. 94).

Como a história do coreógrafo permeia profundamente a história do grupo, e sabendo que ele "superou" uma doença genética ${ }^{8}$ por meio da dança, pode-se compreender a tecnologia tanto como normalizadora quanto restauradora. Na dança do Cena 11, o que é entendido como imperfeições são os limites da materialidade corpórea, ao passo que as tecnologias são vistas como possibilidades, como, por exemplo, as próteses, que ampliam a potência do corpo. Englobam-se as possibilidades reconfiguradoras da tecnologia, para criar criaturas melhoradas, relativamente ao ser humano, ou seja, mais ágeis e fortes, dentre outras características.

Para o espetáculo Skinnerbox, foram desenvolvidos acessórios que distendem o corpo para ele mais bem lidar com o ambiente, de forma a ampliar a qualificação na preparação técnica, e isso parece aproximar as tecnologias ciborguianas como melhoradoras. Constituem criaturas melhores relativas ao ser humano, com o uso dos artifícios que determinam uma amplificação inusitada das capacidades humanas e a busca por lidar bem com o ambiente.

Como existe a busca por certa adaptação e preservação na temática do espetáculo Skinnerbox, a tecnologia vem funcionando, ao mesmo tempo, como normalizadora e melhoradora da relação indivíduo-ambiente-indivíduo. É necessário refletir sobre se essa condição, atrelada à idéia de superação na sociedade hodierna, permeada pelos ideais da ci- 
ência, leva em conta que a própria tecnociência criada pelo capital vem sendo responsável pela deterioração dessa mesma relação. Importante é ressaltar que as melhorias e o progresso não necessariamente garantem que seremos mais felizes, porém, engendram relações ambíguas entre os seres humanos, que necessitam ser tratadas conscientemente.

A função que a tecnologia desempenha na dança do Cena 11, para vencer os limites corporais, compreendida como superpoderes ao ampliar potências, parece permeada pela idéia de progresso. Na ciência, em especial, no âmbito das ciências biomédicas, a máxima moderna de que tudo que é possível deve ser feito faz-se presente e é permeada com sua pretensa neutralidade, objetividade e eficiência.

Indústria e ideologia são voltadas a esse trabalho, subsidiadas por uma ciência e uma tecnologia que, concomitantemente, desprezam os limites da materialidade e exaltam a noção moderna do indivíduo livre, baseada na ambígua e perigosa crença de que se "pode ter o corpo que se quer" (SILVA, 2001, p. 62).

A reconstrução e reestruturação do corpo presentes no processo civilizatório e as modificações corporais extremadas contemporaneamente permeiam a dança, como uma manifestação artística que acompanha a humanidade em sua trajetória. Na dança, esse processo ocorre, e "todas essas práticas sociais que se propõem a ser uma intervenção sobre o corpo têm como fundamento, em maior ou menor grau, os conhecimentos produzidos pela ciência e, em especial, pelas ciências biomédicas" (SILVA, 2001, p. 5).

O grupo compreende as tecnologias como algo que possibilita a superação dos seres humanos diante dos outros animais, assumindo a influência da teoria evolucionista em sua produção. São idéias que permeiam a construção artística do grupo. Como comenta um dos integrantes do grupo:

É essa coisa, até que o Álvaro fala: a lança, o homem é bem mais frágil que um urso, por que que a gente evoluiu bem mais que o urso? Por esse nosso fascínio de conseguir fazer coisas que vão estender a nossa força? A gente não conseguia correr que nem um leopardo daí a gente fez o avião, o que foi que a gente adaptou, pra nossa sobrevivência? 
Com essa perspectiva, os integrantes do Cena 11 põem o próprio desenvolvimento das tecnologias na busca por fortalecer os humanos, tornando-os assim mais adaptados diante dos outros animais e garantindo sua sobrevivência. As relações entre ser humano, tecnologia e outros animais estavam colocadas no espetáculo Skinnerbox, como comenta um dos dançarinos sobre o espetáculo:

Me chamou a atenção por trabalhar com um ser que é a Nina, ${ }^{9}$ bem primitivo, bem eficaz, é claro, porque foi feito um trabalho ali com ela, e um robô que é bem futurístico e o homem. Essa relação é muito interessante. $\mathrm{O}$ homem tá dominando as duas coisas. Tem algum momento que tu podes até viajar que o cachorro domina, que também domina ele. Tá ali, ele também te impede algumas coisas, se não estivesse, tu poderias fazer, mas quem manda ali é o homem, sempre vai mandar. É o homem, independente, a máquina. Ah! O homem que pensou aquilo ali, ele evolui mais que a máquina pra fazer a máquina. Eu não posso ficar inferior à máquina. Como construir uma coisa inferior a ele?[...] O homem só pode ser destruído por ele mesmo. Só homem destrói outro homem, não vai ser a máquina que vai destruir um homem.

Assim, reafirma-se a máxima moderna do homem como senhor da natureza. O projeto científico ocidental parece ter a dominação em sua essência. De certa forma, isso ocorre com os próprios seres humanos envolvidos nesse contexto, tendo de ter controle sobre os animais, sobre as máquinas e sobre si próprios, em suas relações mais intrínsecas, como as sensações de medo, dor, vaidade ${ }^{10}$ para "sobreviverem" como dançarinos do Grupo Cena 11.

São relações de domínio humano sobre a natureza no controle da existência dela, e essa existência, sendo relativa à existência humana, pode ser observada pela presença de Nina na arte da companhia. Em uma das observações de treino, uma dançarina comentou que "Nina foi comprada com mais dois cachorros, e ela foi a escolhida como a mais capaz, que reuniu as qualidades para a função". Isso deixa claro que a Nina existe no grupo por essa finalidade. As qualidades para a função de dançar no grupo foram alcançadas pela cachorra, "que durante dois anos passou por um treinamento com adestrador". Ainda sobre o cachorro, a dançarina comentou que tem de educar o cachorro e o dono ${ }^{11}$ do cachorro, para não perder o treinamento. 
O grupo parece resumir, em alguns momentos, a existência da cachorra às necessidades do próprio grupo. Demonstrou, em muitos momentos, a não-importância da cachorra como ser vivo em si, ressaltando apenas as funções que ela realiza no grupo.

Acerca do Cena 11, o coreógrafo comenta:

Vejo o corpo como um aparato tecnológico (tecnologia = técnica aplicada). A relação com a tecnologia já vem em criar uma técnica ou utilizar uma técnica para alguma coisa. Balet clássico ou jiu-jitsu (técnicas) transformam-se em tecnologia quando são aplicados para, por exemplo, criar dança contemporânea. Óbvio que isso se estende para as relações que o Cena 11 tem com o vídeo, slides... Mas não acho que aí está o nosso forte em tecnologia; isso é o que as pessoas em geral entendem por tecnologia - que é um conhecimento muito pequeno. Não sentimos que o sapato é uma tecnologia, o corpo se adaptou ao sapato. Andar de sapato é uma técnica. E dança é ciência (AHMED, 2003, p. 42).

Essas idéias do coreógrafo possibilitam reflexões importantes para compreender a arte do grupo. Inicialmente, entender o corpo como um aparato tecnológico parece resumi-lo a um objeto que executa técnicas aplicadas, além de reforçar uma concepção dualista de ser humano. Contraditoriamente, essa idéia pode restringir o próprio ser humano e a dominação da natureza atrelada à tecnologia, tal como ocorre desde os primórdios da modernidade, e parece se reafirmar na dominação do corpo que dança no grupo Cena 11. A natureza deixou de ser objeto de contemplação para ser explorada por saberes e práticas sociais.

A idéia de humanidade que não se contrapunha à natureza e que se entendia como parte dela parece ter ficado abandonada. A concepção que fundamenta a tecnociência há muito já mostrava estabelecer as relações entre sujeito e objeto como parâmetros matemáticos. Cabe refletir se essa concepção não permeia a arte do grupo em questão, sobrepondo-se a outras concepções e características antes associadas ao universo da arte.

Em um dos treinos observados, o coreógrafo comenta como os integrantes do grupo teriam de se sentir como uma porta e cair, e não usar outro estímulo, simplesmente cair como uma porta. Um dos integrantes do grupo brinca: "Sou uma porta", e se joga. O coreógrafo 
comenta a idéia de configurar o corpo rápido nas pequenas quedas para agüentar quedas maiores. A arte do grupo parece corroborar a idéia do dançarino, de um objeto que realiza a ação. A tecnologia que parecia ser um dos motes da arte do grupo apresenta-se como continuação dos pensamentos que constituem sua técnica corporal, na qual compreende o corpo como "objeto" que processa informações. Como comenta uma das integrantes do grupo: A "tecnologia tá na maneira de produzir um movimento, $[\ldots]$ a gente trabalha com robô, a gente trabalha com [...], mas nada disso é tecnologia de ponta, isso é uma maneira de ampliar a tecnologia do corpo". O corpo parece entendido como objeto, afirma-se como um dos aparatos tecnológicos da dança prevista.

A separação entre sujeito e objeto parece estabelecer relação com a arte do grupo, engendrando conseqüências ético-políticas de grande importância. A separação entre sujeito e objeto é considerada característica típica da racionalidade científica moderna, que se apresenta indispensável à objetividade científica. $\mathrm{O}$ afastamento do objeto não possibilita que o ser humano se reconheça no objeto, em nome da tão famosa objetividade científica. A extrema separação não parece possível e, com isso, o sujeito não se reconhece mais como tal, pois acaba tendo uma relação a serviço da exploração e dominação da natureza. "Delineia-se já aqui uma espécie de paradoxo em termos lógicos, o distanciamento infinito do sujeito com relação ao seu objeto não constituiria uma objetividade absoluta, mas simplesmente a perda [dele]" (DUARTE, 1988, p. 115). Em nossa sociedade, esse distanciamento não parece ter limite, e juntamente com o desenvolvimento das forças produtivas, esse paradoxo se expressa, em termos político-existenciais, na alienação, na coisificação generalizada. "O desvario universal é, ao mesmo tempo, o seu produto e a condição propícia para o seu florescimento" (DUARTE, 1988, p.117).

Parecem existir algumas contradições referentes ao entendimento de tecnologia e técnica, além das já discutidas de corpo como aparato tecnológico. A dança é constituída por técnicas corporais, seja de balé ou jiu-jitsu, dentre outras, e utilizar outras técnicas não a transforma em tecnologia, e sim coloca novas possibilidades de técnicas corporais para o ato de dançar. A própria utilização de equipamentos e recursos nas movimentações exige determinadas técnicas específicas para rea- 
lizá-las. A idéia fomentada pelo grupo de que andar de sapato é uma técnica parece correta. Andar é técnica e concorda-se com que andar de sapato é a técnica de andar de sapato, pois o aparato influencia a própria técnica corporal executada.

O grupo, porém, entende que o sapato não é uma tecnologia, pois percebe que o corpo se adaptou a ele. Essa adaptação naturaliza para o grupo o aparato tecnológico, considerando-o pertencente à natureza humana. Frente a isso, questiona-se: Se o sapato não é uma tecnologia, por que o corpo que dança o seria? O corpo desenvolve técnicas e, por isso, é considerado um aparato tecnológico para o grupo, e por que o sapato, no qual o ser humano aplica técnica, não é tecnologia? Ainda, questiona-se a utilização do conceito de "aplicar", referente às técnicas corporais que podem ser realizadas para o ato de dançar, visto que possivelmente o conceituado "executar" seria o mais correto. Assim, questiona-se: Se as técnicas de jiu-jitsu e balé clássico fossem utilizadas para andar ou dançar isso as transformaria em tecnologia?

Percebe-se que não existe limiar que possibilite classificar a tecnologia utilizada na dança como boa ou ruim. Entrementes, encontramse relações ambíguas, apresentando questões que merecem atenção, frente à grande valorização do uso da tecnologia no universo artístico com pouca reflexão. Muitos argumentos sustentam-na como pertencente à noção de progresso, o que já permite questionar uma apologia ao presente e um esquecimento das tradições.

A utilização da tecnologia nas produções artísticas é uma das formas pelas quais o ser humano se distancia de uma simples imitação da natureza. Essa concepção de ser humano entendido como um aparato tecnológico parece ser uma negação a tudo que remeta à natureza humana. Essas idéias parecem corroborar o que aponta Huisman sobre uma nova perspectiva de arte, na qual:

Quanto menos ela é natural mais é artística. Uma obra de arte tem necessidade de ser sobre-real para poder ser autêntica. Se a pintura é de extrema monotonia é porque constitui uma imitação servil da natureza. A arte digna desse nome abstém-se de tomar por tema o pôr-do-sol no Adriático ou a pequenez do homem face ao mar Antárctico. Porque ela se sente nesse ponto tão inferior à própria Natureza que não teria nenhuma vantagem em rivalizar com Deus (HUISMAN, 1994, p. 75-76). 
A arte contemporânea é influenciada por seu tempo, no qual as tecnologias, com as mais diversas funções, permeiam-na. A utilização de tecnologias na arte vem se apresentando como tendência, e o Cena 11, de forma geral, é compreendido como um dos grupos que mais inovam no universo da dança. A grande influência do Cena 11 nesse universo coloca-o em um lugar de destaque, tornando-o capaz de ditar e reforçar tendências presentes no universo artístico da dança.

\title{
BREVES CONSIDERAÇÕES
}

As tecnologias entendidas pelo grupo como extensão do corpo são consideradas assim, porque tornam o corpo ainda mais eficiente, ou seja, a extensão do pensamento predominante em nossa sociedade de que tudo deve ser controlado para garantir a produção. A utilização das tecnologias pelo grupo configura-se como estratégia para alcançar os fins desejados, ou seja, a superação dos limites do corpo.

Finalizando estas reflexões, é importante ressaltar que o fato de possuirmos uma consciência apurada sobre nossa existência e sermos capazes de ter técnicas/tecnologias eficazes no manejo do mundo que nos cerca não é predicativo da nossa superioridade como espécie, mas sim um alerta sobre nossas responsabilidades como seres cientes.

Relations between Art and Technology: Cena 11's hybrid dance

\begin{abstract}
This research work tries to understand the relations established between technology and art based on Brazilian dance company Cena 11's proposition of hybrid dance. We have analyzed the company's shows and the dancers' physical preparation based on observation of a set of practice sessions and interviews made with members of the dance company. We have also used part of a dissertation research work from a Master's program in Physical Education from Universidade Federal de Santa Catarina. In this paper we highlight two axes for the analysis of this relation. The first one approaches the understanding that the dancers have of technologies as extensions of the body; the second one discusses the roles that technology has taken in the company's art work and the implications it has had on everyone involved, according to the concept of art that is currently present in the group.
\end{abstract}

KEYWORDS: art - hybrid dance - technology. 


\section{Las relaciones entre Arte y Tecnología: la danza híbrida del Cena 11}

\section{RESUMEN}

El presente trabajo busca comprender las relaciones establecidas entre tecnología y arte a partir de la propuesta de danza híbrida de la Compañía de Danza Cena 11, de Florianópolis/SC. Para eso, se analizaron espectáculos del grupo, la preparación física de los bailarines a partir de la observación de un conjunto de entrenamientos y entrevistas realizadas con los integrantes del grupo, aprovecando parte de una investigación de disertación de Maestría en Educación Física por la Universidad Federal de Santa Catarina. En este artículo, destacamos dos ejes para el análisis de esta relación. El primero abarca la comprensión del grupo sobre las tecnologías como extensión del cuerpo; el segundo versa sobre las funciones asumidas por las tecnologías en el arte del grupo y las implicaciones para aquellos sujetos envueltos, mediante la concepción de arte presente en el grupo.

PALABRAS-CLAVE: arte - danza híbrida - tecnología.

\section{NOTAS}

1 Este é o nome de um dos espetáculos do Grupo, que teve sua estréia em 2005 (Reprod. Vídeo).

2 Pudemos perceber que a atenção dos espectadores estava voltada para o corpo do dançarino, e não para o sapato, pelos comentários feitos por eles na saída do teatro.

3 GRUPO CENA 11. SKR- Procedimento 01. 2004. Reprod. vídeo.

4 Utilizamos a palavra cena para designar modificações na composição do palco.

5 Não se consideram equipamentos tecnológicos, para esta análise, as vestimentas, os recursos de proteção corporal (como exemplo, joelheira), a música e a iluminação.

6 Álvaro é o nome fictício utilizado para identificar o coreógrafo, como forma de preservar suas identidades.

7 Espetáculo estreado em 2000 pelo grupo (Violência. 2001. Reprod. Video).

8 A doença é a osteogênese imperfeita que entre suas características traz um enfraquecimento dos ossos, ocasionando, assim, muitas fraturas.

9 Cachorra do grupo. 
10 Estas afirmações são decorrentes das análises realizadas sobre a preparação física dos dançarinos a qual não apresentamos de forma sistemática neste texto.

11 A cachorra é considerada do grupo e mora com Álvaro.

\section{REFERÊNCIAS}

AHMED, A. Cena 11 - A dança em função do corpo. Revista Combi, Florianópolis, n. 4, agosto-setembro 2003. p.36-46. Entrevista.

BIANCHETTI, L. Da chave de fenda ao laptop, tecnologia digital e novas qualificações: desafios à educação. Petrópolis: Vozes, 2001.

DUARTE, R. A. P. Técnica, Tecnologia, Tecnocracia: algumas observações. Revista Filosófica Brasileira, Rio de Janeiro: UFRJ, v. 4, n.2, p.111-118, outubro, 1988.

HUISMAN, D. A estética. Lisboa: Edições 70, 1994.

MCLUHAN, M. Os meios de comunicação como extensão do homem. 14. ed. São Paulo: Cultrix, 2005.

SILVA, A. M. Corpo, ciência e mercado: reflexões acerca da gestação de um novo arquétipo da felicidade. Florianópolis: UFSC, 2001.

SILVA, T. T. Nós, ciborgues: o corpo elétrico e a dissolução do humano, In: _ (Org.). Antropologia do ciborgue - vertigens do pós-humano. Belo Horizonte: Autêntica, 2000. p.11-17.

SPANGHERO, M. A dança dos encéfalos acesos. São Paulo, SP: Itaú Cultural, 2003.

Recebido: 30 de março de 2007

Aprovado: 6 de junho de 2007

Endereço para correspondência: elisaabrao@yahoo.com.br

236 ABRÃO, E. As relações entre arte e tecnologia: a dança híbrida do Cena 11 